\title{
Is acute calcific tendinitis in the wrist unrecognized and under-reported?
}

\author{
Neil J Wells BSc MD, Nicholas J Carr MD FRCSC \\ Division of Plastic Surgery, University of British Columbia, Department of Surgery, \\ Vancouver General Hospital, Vancouver, British Columbia
}

\begin{abstract}
NJ Wells, NJ Carr. Is acute calcific tendinitis in the wrist unrecognized and underreported? Can J Plast Surg 1995;3(3):142-144. Acute calcific tendinitis is currently thought to be a rare entity in the wrist, with few reports in the surgical literature. We review five cases seen in our institution in an eight-month period and question whether this entity is increasing in frequency or misdiagnosed, leading to underreporting.
\end{abstract}

Key Words: Acute calcific tendinitis, Wrist

La tendinite calcifiante aiguë du poignet est-elle suffisamment reconnue et déclarée ?

RÉSUMÉ : La tendinite calcifiante aiguë est à l'heure actuelle perçue comme une maladie rare du poignet, ayant fait l'objet de peu de rapports dans la littérature chirurgicale. Nous passons en revue cinq cas observés dans notre établissement au cours d'une période de huit mois et nous nous demandons si cette maladie est en hausse, si elle n'est pas sous-diagnostiquée et insuffisamment rapportée.

Calcific tendinitis, which is commonly found in the shoulder, is well known to orthopedic and rheumatologic practitioners. There are numerous articles in both groups' literature reporting cases at unusual sites including the wrist and hand. However, since the first description in 1924 (1) there have been only two articles in the hand or plastic surgery literature $(2,3)$. It is probably because of its infrequency in the wrist and hand, and the lack of reference to it in the hand surgery literature, that it is often not entertained as a diagnosis in patients with an acutely painful hand. This lack of awareness can lead to a delay in diagnosis, a delay in treatment and unnecessary interventions.

This paper reviews five cases of volar wrist calcific tendinitis seen in an eight month period at a tertiary referral centre. The clinical presentation, diagnostic tests used, treatment and outcome in these patients are described and the current literature reviewed.

\section{MATERIALS AND METHODS}

During an eight-month period, five patients were seen in consultation by the hand surgery service and were subsequently diagnosed as having acute calcific tendinitis in the wrist. A retrospective analysis, using patient records, and follow-up examinations were 
carried out to identify the patient profile, clinical presentation, referral diagnoses, value of diagnostic tests, treatments and outcome.

All patients had an initial radiograph and were seen within two days of the onset of symptoms. No patient had a previous history of gout, calcinosis, calcium metabolism imbalance, nor any significant family history. There were no inflammatory changes at other joints.

\section{RESULTS}

The clinical data for the five patients are presented in Table 1. Two patients had a vague history of antecedent trauma (patient 2 suffered a twisted hand one week before examination and patient 4 fell on hand six weeks before); however neither had any problems before the time of presentation. One had a history of a repetitive activity (pushups) for the month before presentation.

TABLE 1: Patient profiles, referring diagnosis, clinical findings, laboratory results and radiographic interpretation in the five patients

\begin{tabular}{|l|l|l|l||l|l||}
\hline & Patient 1 & Patient 2 & Patient 3 & Patient 4 & Patient 5 \\
\hline Age & 75 & 31 & 43 & 72 & 59 \\
\hline Sex & Female & Female & Male & Male & Female \\
\hline $\begin{array}{l}\text { Referring } \\
\text { diagnosis }\end{array}$ & $\begin{array}{l}\text { Septic } \\
\text { arthritis }\end{array}$ & $\begin{array}{l}\text { Scaphoid } \\
\text { fracture }\end{array}$ & Tenosynovitis & $\begin{array}{l}\text { Wrist } \\
\text { fracture }\end{array}$ & $\begin{array}{l}\text { Septic } \\
\text { arthritis }\end{array}$ \\
\hline Pain & Moderate & Severe & Moderate & Severe & Moderate \\
\hline Swelling & Moderate & Moderate & Mild & Mild & Moderate \\
\hline Erythema & Yes & Yes & Yes & Slight & Yes \\
\hline Warmth & Yes & Yes & Yes & No & Yes \\
\hline ROM & Decreased & Decreased & Decreased & Decreased & Normal \\
\hline $\begin{array}{l}\text { Laboratory } \\
\text { results }\end{array}$ & ESR 48 & N/A & N/A & $\begin{array}{l}\text { CBC } \\
\text { normal }\end{array}$ & ESR 20 \\
\hline $\begin{array}{l}\text { X-ray } \\
\text { interpretation }\end{array}$ & $\begin{array}{l}\text { Joint } \\
\text { calcification }\end{array}$ & $\begin{array}{l}\text { Scaphoid } \\
\text { chips }\end{array}$ & $\begin{array}{l}\text { Extranumery } \\
\text { bone }\end{array}$ & $\begin{array}{l}\text { Bone } \\
\text { fragment }\end{array}$ & $\begin{array}{l}\text { Joint } \\
\text { calcification }\end{array}$ \\
\hline
\end{tabular}

CBC Complete blood count; ESR Erythrocyte sedimentation rate; N/A Not applicable; ROM Range of motion

The initial diagnoses included infection and trauma and were incorrect in all referrals. The time to diagnoses ranged from immediate to one week. All patients had radiographs done which revealed calcification in the wrist at the level of the radiocarpal joint (Figure 1). Three were in the vicinity of the flexor carpi radialis, one in the long finger flexors, and one in the extensor carpi radialis tendons. Although all films revealed an abnormality, none were interpreted by the radiologist to be acute calcific tendinitis. 

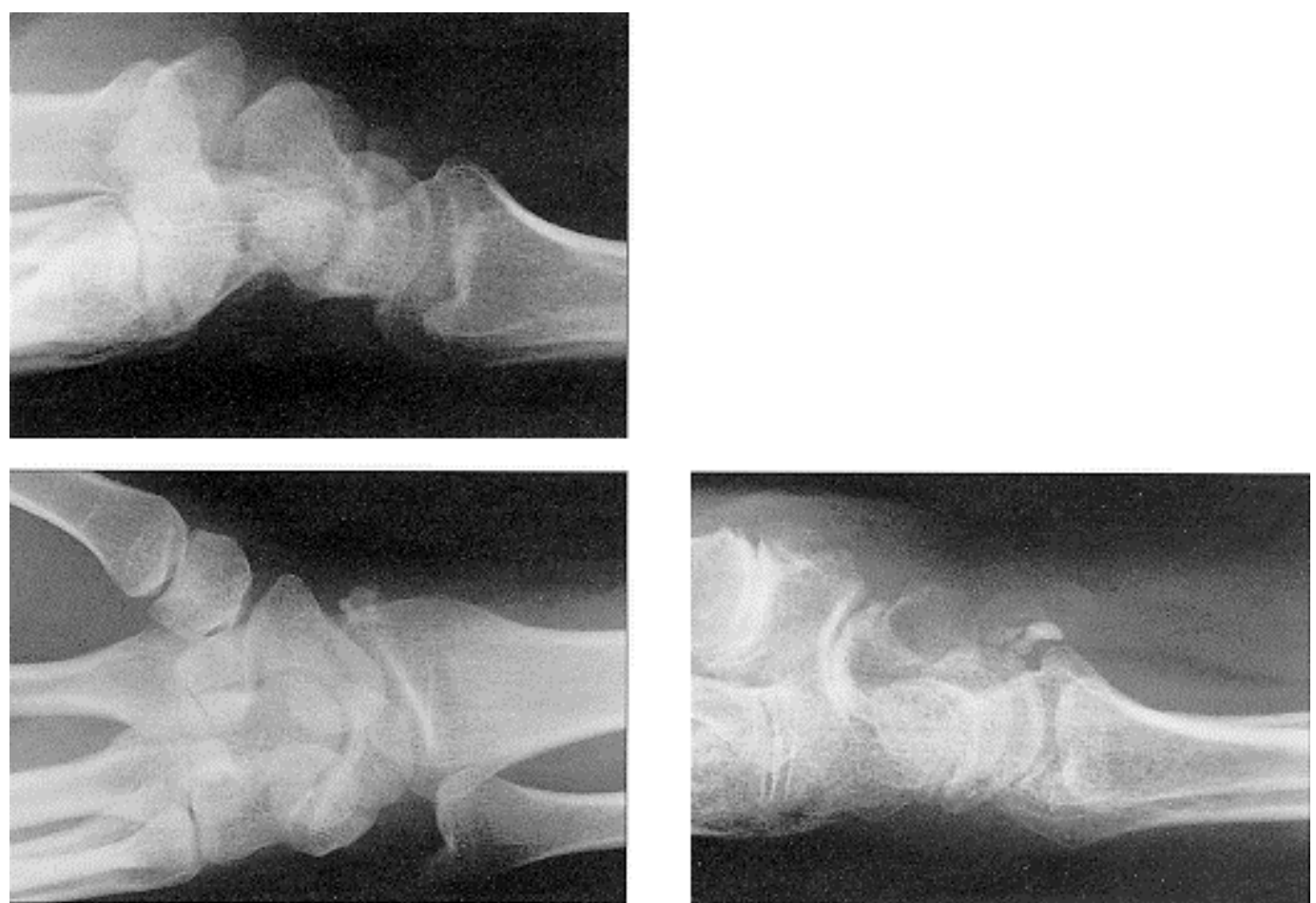

Figure 1) Lateral (top left) and anteroposterior (AP) (bottom left) radiographs of patient 3 showing the location of the calcification and the appearance on $x$-ray. A second patient (\#1) demonstrating the extent of calcification (right)

Patient 4 presented with an acute onset of left wrist pain that kept him awake at night and increased with activity. Prior to referral he was splinted and had temporary relief but then deteriorated on the day of admission with increasing pain and thenar weakness but a normal two point discrimination. He had a radiograph and competerized tomographic (CT) scan which were interpreted as being a bone fragment compressing the median nerve (Figure 2). Subsequently he underwent a carpal tunnel release and excision

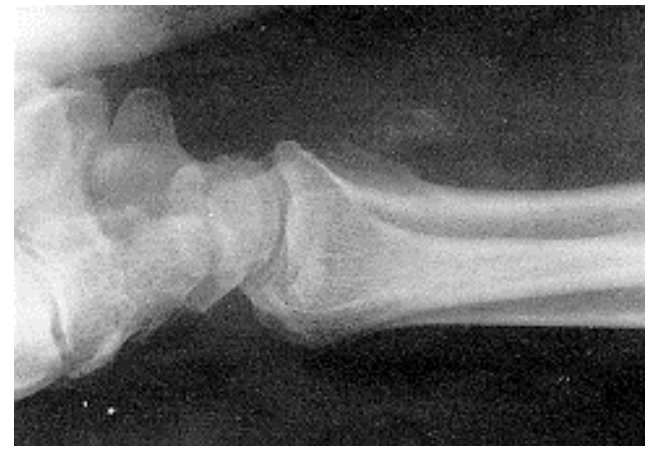

Figure 2) Lateral radiograph of patient 4 at the time of presentation. This was interpreted by the radiologist as being $a$ bone fragment from a previous wrist fracture

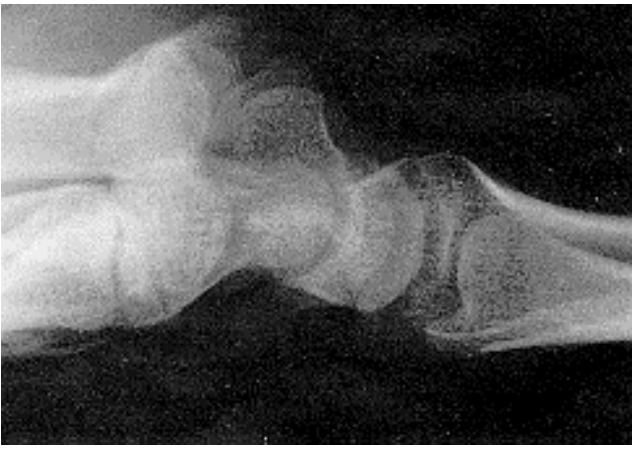

Figure 3) Patient 3 (Figure 1, top left) two months after initial presentation. Note the extent of resorption of the calcification. The patient is asymptomatic at this time and has resumed his usual activities 
of a calcific mass from his flexor tendons. Intraoperatively he was noted to have a milky substance around the flexor tendons in his carpal tunnel. Bacteriologic studies were negative and pathology revealed ectopic bone formation in the tendon and sheath. $\mathrm{He}$ improved postoperatively and was discharged home with a splint and was subsequently diagnosed as having acute calcific tendinitis.

All patients presented with a sudden onset of symptoms which objectively improved in a week with splinting and a nonsteroidal anti-inflammatory drug.

\section{DISCUSSION}

Cohen in 1924 was the first to describe acute calcification in the hand and since then numerous authors have described sporadic cases in the hand (2-9). The largest series is by Yelton and Dickey (1958) who reported on 209 cases in the hand and wrist. In reviewing the literature only two references $(2,3)$ could be found in hand or plastic surgery literature -- a report of three cases by Dilley and Tonkin in 1991 (2) and a case report in a child by Millon et al in 1993 (3). Our findings of five cases in eight months, compared with one every two years in a retrospective 10 year chart review at our institution, leads to the possibility that this entity has been previously unrecognized or is increasing in frequency. The likely explanation is that these patients present to the emergency room or family physician with symptoms that are interpreted as either an infection or an undisplaced fracture which is treated with immobilization antibiotics. They likely improve with the immobilization; however the diagnosis is missed. Our increased frequency is likely a result of our increased interest and education of the emergency room physicians.

In all these articles the presentation was similar, with acute pain, swelling, erythema, decreased range of motion and radiographic findings of heterotopic calcification. The most frequent location in the published cases was in the flexor carpi ulnaris tendon at the wrist (2). In this series three were found in the region of the flexor carpi radialis tendon, one in the flexor digitorum profundus tendons and one in the extensor carpi radialis tendons.

The cause for this condition is unclear; however, Carroll et al (10) postulated trauma and repetitive use as risk factors. Three patients in this series had a history of either of these. Local hypoxia has also been proposed as the initiating factor leading to tendon degeneration and calcification by chondrocytes. Gartner and Simons (11) analyzed the deposits from operative specimens and demonstrated that they were composed of a crystallized hydroxyapatite lattice (resembling bone) which appear as a milky emulsion in the acute phase (such as in patient 4), and a granular conglomerate in the chronic phase. In our series radiographs demonstrated dense circumscribed calcifications in the area of maximal tenderness on clinical examination; however, despite these findings, in no case was an accurate diagnosis made by the radiologist. It has been suggested that CT scan may play a role in the diagnosis of unusual cases (12). In the one case in this series in which CT scanning was used, unnecessary surgical intervention was not averted. The prognosis in acute calcific tendinitis is very good with a reported resolution of symptoms in untreated individuals in three weeks and within one week in patients (such as those in this study) treated with nonsteroidal anti-inflammatory drugs (NSAIDS) and splinting. Radiographs show resolution of the calcification as early as two weeks post treatment (Figure 3). In light of this rapid clinical course it is important to 
ascertain the diagnosis early and prevent unnecessary intervention which can delay eventual functional recovery. In this series the initial referring diagnosis was incorrect in all cases. Since infection and fractures are important conditions and can lead to significant problems if missed, it is reasonable to include these initially in the differential diagnosis. If a patient presents with erythema, pain and ectopic calcification on radiographs, without a good history of trauma or other findings consistent with an infection, acute calcific tendinitis must be considered in the differential diagnosis. Increased awareness of this condition should lead to an earlier diagnosis without subjecting the patient to unnecessary interventions such as CT scanning, blood tests and surgery.

ACKNOWLEDGEMENTS: We would like to thank Dr J Boyle and Dr B Foley for providing us with their patients and medical charts. We would also like to thank Dr DJ Courtemanche for his assistance with the manuscript.

\section{REFERENCES}

1. Cohen I. Calcereous deposit at the insertion of flexor carpi ulnaris tendon following trauma. Am J Surg 1924;38:172-3.

2. Dilley DF, Tonkin MA. Acute calcific tendinitis in the hand and wrist. J Hand Surg 1991;16B:215-6.

3. Millon JS, Bush DC, Harrington TM. Acute calcific tendinitis in a child: A case report. J Hand Surg 1993;18A(4):592-3.

4. Moyer RA, Bush DC, Harrington TM. Acute calcific tendinitis of the hand and wrist: a report of 12 cases and a review of the literature. J Rheumatology 1989;16:198-202.

5. Wulle C, Heim U. Peritendinitis calcarea of the hand, a case report. Handchirurgie, Mikrochirurgie, Plastische Chirurgie 1990;22:92-5.

6. Shaw JA. Acute calcific tendinitis in the hand. Orthopedic Review 1986;15:482-5.

7. Selby CL. Acute calcific tendinitis of the hand: an infrequently recognized and frequently misdiagnosed form of periarthritis. Arthritis and Rheumatism 1984;27:337-40. 8. Greene TL, Louis DS. Calcifying tendinitis in the hand. Ann Emerg Med 1980;9:43840.

9. Yelton CL, Dickey LE. Calcification about the hand and wrist. Southern Med J 1958;51:489-95.

10. Carroll RE, Sinton W, Garcia A. Acute calcium deposits in the hand. JAMA 1955; 157:422-6.

11. Gartner J, Simons B. Analysis of calcific deposits in calcifying tendinitis. Clin Orthop Related Res 1990;254:111-20.

12. Archer BD, Friedman L, Stilgenbauer S, Bressler H. Symptomatic calcific tendinitis at unusual sites. Can Assoc Radiol J 1992;43:203-7. 